\title{
Establishment and characterization of a pair of non-malignant and malignant tumor derived cell lines from an African American prostate cancer patient
}

\author{
SHANIECE THEODORE ${ }^{1}$, STARLETTE SHARP ${ }^{1}$, JIANJUN ZHOU ${ }^{1}$, TIMOTHY TURNER ${ }^{1}$, HONGZHEN LI $^{2}$, \\ JUN MIKI $^{2}$, YOUNGMI JI ${ }^{2}$, VYOMESH PATEL ${ }^{3}$, CLAYTON YATES ${ }^{1}$ and JOHNG S. RHIM ${ }^{2}$ \\ ${ }^{1}$ Department of Biology and Center for Cancer Research, Tuskegee University, Tuskegee, AL; ${ }^{2}$ Center for Prostate \\ Disease Research, Department of Surgery, Uniformed Services University of the Health Sciences, \\ Bethesda, MD; ${ }^{3}$ Oral and Pharyngeal Cancer Branch, NIDCR, NIH, Bethesda, MD, USA
}

Received June 2, 2010; Accepted July 16, 2010

DOI: 10.3892/ijo_00000800

\begin{abstract}
Research into molecular and genetic mechanisms underlying prostate carcinogenesis in high-risk African American men would be greatly advanced by in vitro models of African American prostate tumors representing primary tumors. However, the generation of immortalized primary African American prostate cancer cells that will accurately reflect the in situ characteristics of malignant epithelium is currently limited but is greatly needed. We have successfully established immortalized cell lines of a pair of non-malignant and malignant tumors derived from an African American prostate cancer patient with HPV-16E6E7 (RC-77N/E and $\mathrm{RC}-77 \mathrm{~T} / \mathrm{E})$. RC-77N/E and RC-77T/E cells are currently growing well at passage 40 . Both cells exhibit epithelial morphology and are androgen sensitive. The RC-77T/E cells produced tumors in SCID mice whereas the RC-77N/E cells produced no tumor in SCID mice. These cells expressed androgen-regulated prostate-specific homobox gene, NKX 3.1, epithelial cell specific cytokeratn 8 , androgen receptor (AR), prostate specific antigen (PSA), and p16. Chromosome analysis showed that both cell lines are similar; near diploid human male (XY) with most chromosome counts in the 45-48 range. However, RC-77T/E cell line has new marker chromosomes: $\mathrm{M} 1 \mathrm{~B}=\mathrm{del} / \mathrm{t}(4 ; ?)(\mathrm{q} 28 ; ?), \mathrm{M} 5=16 \mathrm{q}+$ in addition to those observed
\end{abstract}

Correspondence to: Dr Clayton Yates, Department of Biology and Center for Cancer Research, Tuskegee University, Tuskegee, Carver Research Foundation, Rm \#22, Tuskegee, AL 36088, USA

E-mail: cyates@tuskegee.edu

Dr Johng S. Rhim, Center for Prostate Disease Research, Department of Surgery, Uniformed Services University of the Health Sciences, 4301 Jones Bridge Road Bethesda, MD 20814, USA

E-mail: jrhim@verizon.net

Key words: African American prostate cancer, non-malignant and malignant cell lines in the RC-77N/E cell line $(\mathrm{M} 1=\operatorname{del}(4)(\mathrm{q} 28 \mathrm{q} 34)+\mathrm{hsr}$ in some, $\mathrm{M} 1 \mathrm{~A}=\mathrm{t}(4 \mathrm{q} ;$ ?),M2=der(9?),M2A=del(M2p-),M3=iso(?), M4=der(22?)). This is the first documented case of the establishment of pair of non-malignant and malignant tumors derived from an African American prostate cancer patient. These models will provide novel tools to study the molecular and genetic mechanisms of prostate carcinogenesis, especially for high-risk African American men.

\section{Introduction}

Prostate cancer is the most common male cancer in the United States, as well as in the Western world, and the second leading cause of the male cancer death in the USA (1). African American men have a $60 \%$ higher incidence and mortality rates from prostate cancer compared to Caucasian men in North America, indicating that prostate cancer is a major public health problem in this population (1). The etiology of these racial differences in the clinical manifestation of prostate cancer is unclear; hormonal, genetic, behavioral and environmental factors have all been implicated (2). To understand the many factors suspected of contributing to the development of this malignancy, there is a critical need for in vitro models representing primary tumors. However, no suitable in vitro models which accurately reflect the in situ characteristics of malignant epithelium for the study of African American prostate cancer are available.

To date, only two reports have documented the establishment of African American prostate cancer-derived human prostate cancer cell lines; MDA PCa $2 \mathrm{a}$ and MDA PCa 2b cell lines were derived from a single bone metastasis (3). These cell lines exhibit androgen-independent growth in vitro and in vivo, however retain androgen responsiveness. A second cell line was derived from primary localized adenocarcinoma of the prostate. The E006AA cell line was established as spontaneously immortalized cells from a patient with a clinically localized prostate cancer. However, this cell line shows androgen-dependent growth but is not tumorigenic in nude mice (4) thus leaving a void in a long-term human cell line that has tumorigenic potential. Here, we report for the first time the establishment of a novel pair of non-malignant 
and malignant tumor-derived from an African American prostate cancer patient.

\section{Materials and methods}

Generation of primary cell cultures. The tumor tissue (RC-77T) and non-malignant tissue (RC-77N) used for generating the cell lines were obtained from radical prostatectomy specimen of a 63-year old African American patient according to Water Reed Army Medical Center and the Uniformed Services University of the Health Sciences Internal Review Board Protocol. This patient had clinical stage T3c adenocarcinoma with poor differentiation (Gleason 7). Nonmalignant cells were derived from non-cancerous regions that were confirmed by histopathological examination. The method for generating primary prostate cell cultures has been described (5). Briefly, the tumor and non-malignant tissue obtained by an experienced pathologist was chopped into small fragments, 1-2 mm in size with a sterile blade. The small cell clumps were placed into several type 1 collagen-treated dishes (BectonDickinson, Boston, MA) containing growth medium and were allowed to attach for a week to the bottom surface of the culture dishes. The cells were incubated at $37^{\circ} \mathrm{C}$ in a humidified air of $5 \% \mathrm{CO}_{2}$ until reaching semi-confluency. Aliquots of the primary cultures were then frozen and stored in liquid nitrogen until the cells were re-established in secondary culture for additional serial passages. For serial passages, routine trypsinization was used once a week in the collagen-treated culture dishes, and the split ratio of the cells was 1-2. Keratinocyte serum-free medium (K-SFM) supplemented with bovine pituitary extract and recombinant epidermal growth factor (Life Technologies, Inc., Gaithersburg, MD) was used for growing and maintaining the cells.

Generation of RC-77T/E and RC-77N/E cell lines. At passage 4, the actively proliferating RC-77T and RC-77N cells grown in $\mathrm{K}-\mathrm{SFM}$ with supplements were infected with a recombinant retroviral construct, LXSN-HPV16E6E7 (generously provided by Dr D.A. Galloway, Seattle, WA) containing the E6 and E7 genes of HPV-16 and a neomycin resistance gene (6). Briefly, cells were transduced through infection using polybrene at the concentration of $10 \mu \mathrm{g} / \mathrm{ml}$ and incubated at $37^{\circ} \mathrm{C}$ in $5 \% \mathrm{CO}_{2}$ overnight. The infected cells were washed with PBS, then incubated and subcultured weekly for further serial passages. No G418 selection was necessary because the uninfected RC-77T and RC-77N cells senesced at passage 6.

RT-PCR assay. RT-PCR assay was done as previously described (7). Briefly, total RNAs from culture cells were extracted with RNAzol B (TEL-TEST Inc., Friedswood, TX) according to the manufacturer's protocol and quantified with Nucleic Acid Quantitation Kit (NBI, Plymouth, MN). Total RNA $(1 \mu \mathrm{g})$ was reverse transcribed into cDNA with RNA PCR kit (Perkin-Elmer, Foster, CA) and 1/10 of the reverse-transcribed product from each sample was used for PCR to amplify AR, NKX3.1, CK8, and HPV-16E6 genes respectively. The expression of CK8 was used as an internal control for input RNA as well as the marker for epithelial cells. To verify the validity of CK8 as the internal control, we compared CK8 and the house-keeping gene, GAPDH in the same cDNA samples. The condition of PCR for the individual gene was optimized to analyze the amplified product in the linear range of amplification by adjusting amplification cycles for each set of primers. The primer sequences and the expected size of PCR products were the same as described (7).

Androgen growth response. To determine the effects of androgen stimulation on the growth of RC-77N/E and RC$77 \mathrm{~T} / \mathrm{E}$ cells, $2 \times 10^{4}$ cells per well were grown in serum-free $\mathrm{K}-\mathrm{SFM}$ with $0.1 \% \mathrm{BSA}$ in the presence of $0,0.1,1.0,10.0$ and $100.0 \mathrm{nM}$ for 4 days. K-SFM was supplemented with or without Methyltrienolone (R1881) (Perkin-Elmer, Waltham, MA), at concentrations of $0.1,1,10$ and $100 \mathrm{nM}$, respectively. Cell proliferation was determined by MTT assay was previously described (8).

Three-dimensional culture of prostate cells in rotating wall vessel $(R W V)$. Three-dimensional RWV conditions were preformed as previously described (9). Briefly, $2 \times 10^{7} \mathrm{RC}-77 \mathrm{~N} / \mathrm{E}$ or $\mathrm{RC}-77 \mathrm{~T} / \mathrm{E}$ cells, respectively, were seeded in $\mathrm{RWV}$ in serum-free KGM media and stopped and the prostate organoids and medium was collected on respective days. The extent of three-dimensional structure formation was determined by measuring the disappearance of single cells using the Coulter Counter Z1. The index of the degree of individual cells incorporated into organoids was measured utilizing the formula $100 \mathrm{X}$ (N0/ND), where N0 is the total cell number input and ND is the total number of particles/cells after respective days of incubation as determined by counting in a Coulter Counter Z1 (10). Organoids were harvested, and fixed with $1 \%$ formaldehyde and sectioned for histopathology. Images were taken with DSU Confocal Unit, Olympus. Images were processed with Metamorph software.

Tumorigenicity in SCID mice. To determine tumorigenicity, $1 \times 10^{7}$ cells in $0.2 \mathrm{ml}$ of PBS were injected subcutaneously into the mid-dorsal intracapular region of adult male SCID mice. The mice were observed for 6 months for tumor development.

Cytogentic analysis. Chromosome counts, ploidy distribution, and Giemsa (G)-banded karyotypes were prepared by standard protocol as described previously $(11,12)$.

\section{Results}

To determine whether human prostate cancer cells will become immortalized by the expression of HPV-16E6E7, we introduced a retrovirus construct expressing HPV-16E6E7 into third-passaged RC-77N/E and RC-77T/E cells through overnight infection. Non-infected cells could not be propagated serially beyond 5 subcultures. In contrast, the HPV-16E6E7infected RC-77N/E and RC-77T/E cells have an apparently unlimited lifespan and have been successfully subcultivated for $>40$ passages over the course of 1 year with no evidence of decreased proliferation capacity (Table I).

The RC-77N/E and RC-77T/E cells had typical epithelial morphology (Fig. 1). The cells grew as adherent cells and were more piled-up on each other in some areas. To confirm 
Table I. Properties of RC-77T/E and RC-77N/E cell lines.

\section{$\mathrm{RC}-77 \mathrm{~T} / \mathrm{E} \quad \mathrm{RC}-77 \mathrm{~N} / \mathrm{E}$}

\begin{tabular}{lcc}
\hline Life span $(>40$ passages $)$ & $>40$ & $>40$ \\
Gene expression by RT-PCR & & + \\
E6 & + & + \\
NKX3.1 & + & + \\
Cytokeratin 8 & + & + \\
AR & + & + \\
p16 & + & - \\
PSA & + & + \\
GAPDH & + & - \\
3D-organoid formation & + & $0 / 3$ \\
Tumorigenicity in SCID mice & $3 / 3$ & \\
\hline
\end{tabular}

that the immortalized $\mathrm{RC}-77 \mathrm{~N} / \mathrm{E}$ and $\mathrm{RC}-77 \mathrm{~T} / \mathrm{E}$ contain the transduced HPV-16E6E7 gene, RT-PCR was carried out with $1532 \mathrm{~T}$ cells as positive control and DU145 cells as negative control. The expression of HPV-16E6 gene was detected in both cell lines and $1532 \mathrm{~T}$ cells but not DU-145 cells (Fig. 1B). $\mathrm{RC}-77 \mathrm{~T} / \mathrm{E}$ and $\mathrm{RC}-77 \mathrm{~N} / \mathrm{E}$ cells were also analyzed to determine the expression of specific markers by RT-PCR. Table I shows a summary of markers expressed in both cell lines. Androgen-regulated prostate specific homobox gene, NKX3.1, an epithelial cell-specific cytokeratin (CK) 8, androgen receptor (AR), and p16 were expressed in both cell lines. Additionally, PSA expression was determined by realtime PCR and immunofluorescence.

Since we observed androgen receptor expression in both cell lines we next examined if the RC-77N/E and RC-77T/E cell lines were sensitive to androgen treatment. Cells were grown in serum-free K-SFM at different doses of R1881 for 4 days. RC-77T/E cells were responsive to $0.1 \mathrm{nM} \mathrm{R} 1881$, however RC-77N/E cells were only responsive at the higher dosage of $1 \mathrm{nM}$. Significant stimulation in cell growth was observed for RC-77T/E cells and RC-77N/E cells at $1.0 \mathrm{nM}$ R1881, however $100.0 \mathrm{nM}$ R1881 resulted inhibition of cell growth (Fig. 1C).

Formation of non-adherent three dimensional organoids could possibly serve as a criterion for in vitro tumor forming potential $(13,14)$. In order to determine whether cells demonstrated this characteristic, $2 \times 10^{7}$ of both $\mathrm{RC}-77 \mathrm{~N} / \mathrm{E}$ and $\mathrm{RC}-77 \mathrm{~T} / \mathrm{E}$ cells were introduced to the RWV system. The $\mathrm{RC}-77 \mathrm{~T} / \mathrm{E}$ malignant-derived cells formed three dimensional tissue structures over a 5-day period. Histopathological analysis of organoids showed tumor tissue-like structures (Fig. 2i and ii). Vertically all RC-77T/E cells where cohesive, as measured by number of suspended cells after each time interval, with maximal incorporation of individual cells into organiods at day 3 of RWV culture (Fig. 2iii). All RC-77N/E cells remained suspended as single cells, and we did not observe any significant organoid formation.

To determine tumorigenicity in vivo for the $\mathrm{RC}-77 \mathrm{~T} / \mathrm{E}$ (passage 45) and RC-77N/E (passage 45) cell lines, $1 \times 10^{7}$ cells were injected subcutaneously into SCID mice. All the animals inoculated with $\mathrm{RC}-77 \mathrm{~T} / \mathrm{E}$ cells developed tumors within $4 \frac{1}{2}$ months at the site of inoculation and the tumors reached $10 \mathrm{~mm}$ size at 6 months (Table I). Microscopic examination
A.
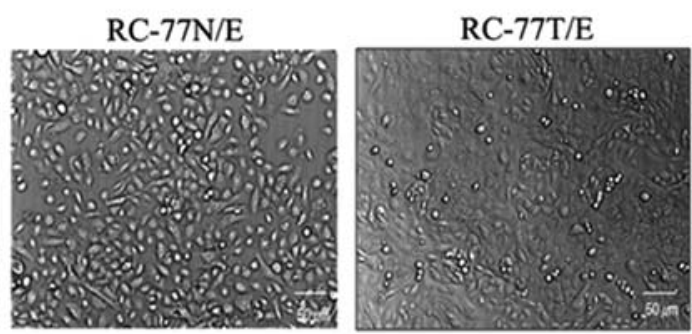

c.

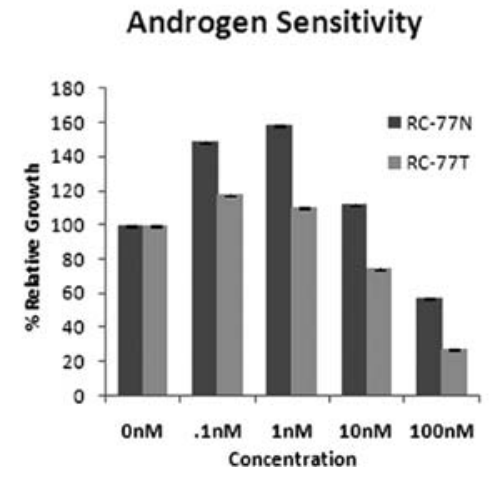

B.

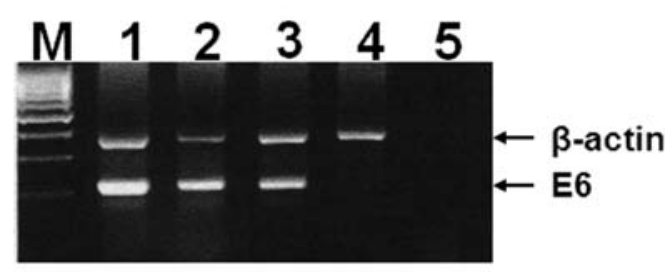

Figure 1. Characteristics of the RC-77T/E and RC-77N/E cell lines. (A) Morphology of cell lines RC-77N/E (left) and Rc-77T/E (right). These cultures show typical epithelial morphology. (B) To verify the integrated E6 and E7 genes of HPV-16 into the RC-77T/E and Rc-77N/E cell line, RT-PCR with E6 primer was carried out. The strong expression of E6 gene (210 bp) was detected in both RC-77T/E cells (passage 25) (lane 1) and RC-77N/E (passage 25) (lane 2) $1532 \mathrm{~T}$ cells (lane 3) as positive control and DU145 cells (lane 4) was negative control. Expression of $\beta$-actin gene (315 bp) was presented here as internal positive PCR control and $\mathrm{H}_{2} \mathrm{O}$ as negative control. (C) Androgen sensitivity assay. Sensitivity to R1881 was assessed for $\mathrm{RC}-77 \mathrm{~T} / \mathrm{E}$ and $\mathrm{RC}-77 \mathrm{~N} / \mathrm{E}$ cell lines in serum-free K-SFM with $0.1 \%$ BSA in the presence of $0,0.1,1.0,10.0$ and $100.0 \mathrm{nM}$ for 4 days. Significant differences in cell growth was observed for RC-77T/E cells and Rc-77N/E cells at $1.0 \mathrm{nM} \mathrm{R} 1881$ in stimulation and $100.0 \mathrm{nM}$ R1881 showed inhibition. The number of cell counts were expressed as mean value of triplicate observation. 
A.
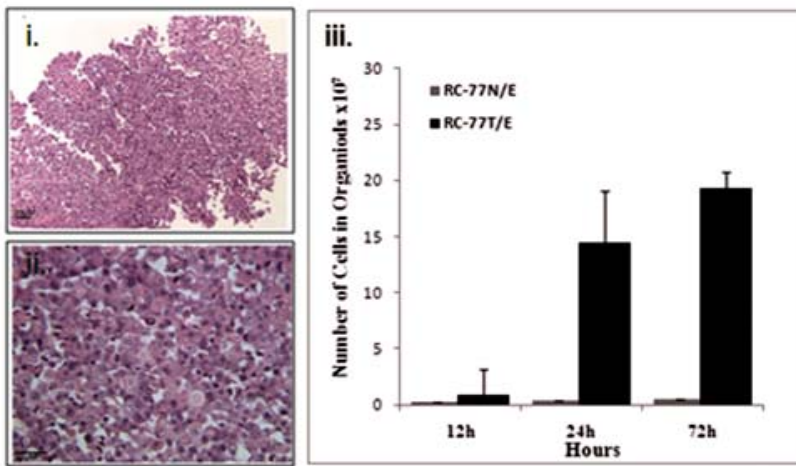

C.

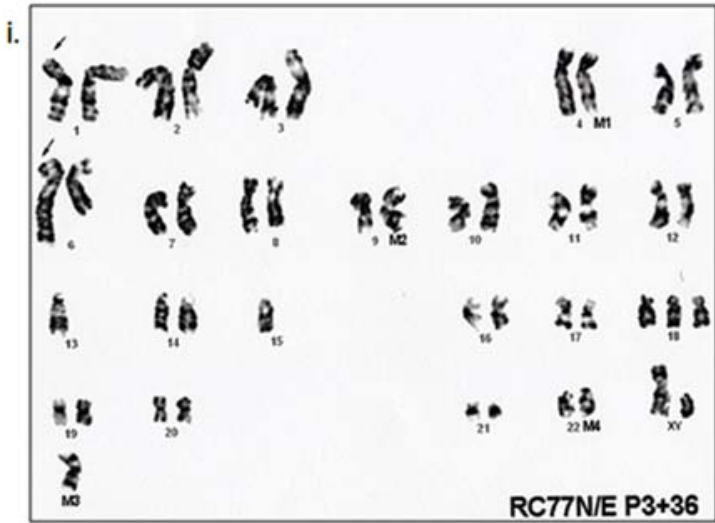

ii.

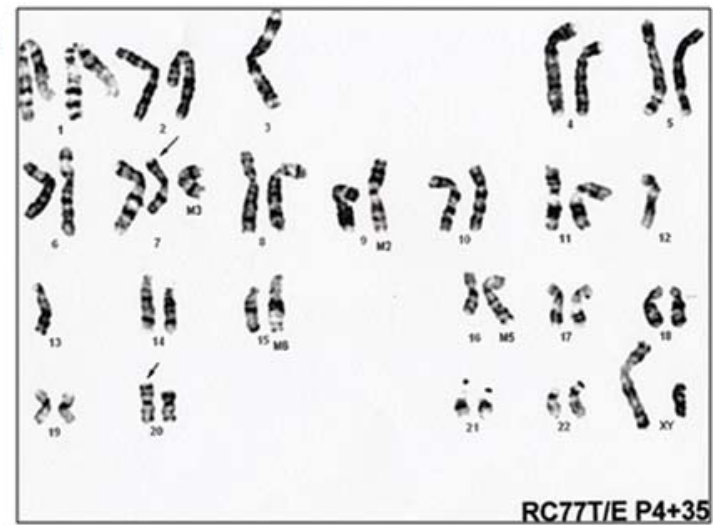

Figure 2. Tumorigenicity of RC-77T/E and RC-77N/E cell lines. (A) Three-dimensional structure formation by RC-77T/E cells (i and ii). Number of cells in organoid formed by RC-77T/E cells was significantly higher than those formed by RC-77N/E cells (iii). Three-dimensional structure formation was not detectable in RC-77N/E cells. (B) Poorly differentiated adenocarcinoma produced by inoculation of the RC-77T/E cell line into SCID mice. (C) Karyotypes of RC-77N/E (passage 39) (upper) and RC-77T/E (passage 39) (lower) cell lines. Four marker chromosomes were detected in RC-77N/E cell line whereas six marker chromosomes were detected in RC-77T/E cell line.

Table II. Karyological characterization of RC-77T/E and RC-77N/E cell line.

\begin{tabular}{lcc}
\hline Cell lines & $\mathrm{RC}-77 \mathrm{~T} / \mathrm{E}$ & $\mathrm{RC}-77 \mathrm{~N} / \mathrm{E}$ \\
(Passage) & $(\mathrm{P}-39)$ & $(\mathrm{P}-39)$
\end{tabular}

Ploidy

Chromosome count

Modal number

Normal chromosomes

Marker chromosomes
Near diploid human male

45-48

46

Single $\mathrm{X}$ and $\mathrm{Y}$ in each karyotype

8

$\mathrm{M} 1=\operatorname{del}(4)(\mathrm{q} 28 \mathrm{q} 34)+\mathrm{hsr}$ in some

$\mathrm{M} 1 \mathrm{~A}=\mathrm{t}(4 \mathrm{q} ; ?)$

$\mathrm{M} 1 \mathrm{~B}=\mathrm{del} / \mathrm{t}(4 ?)(\mathrm{q} 28 ; ?)$

M2=der(9?)

M3=iso(?)

M4=der(22?)

M5=16q+

M6 $=15 p+$
Near diploid human male

45-48

47

Single $\mathrm{X}$ and $\mathrm{Y}$ in each karyotype

6

M1=del(4)(q28q34)+hsr in some

$\mathrm{M} 1 \mathrm{~A}=\mathrm{t}(4 \mathrm{q} ; ?)$

M2=der(9?)

M2A=del(M2p-)

M3=iso(?)

M4=der(22?) 
of section of the tumor revealed poorly differentiated adenocarcinoma (Fig. 2B). However, no tumor formation was detected in animals inoculated with RC-77N/E cells for the 6-month observation period of tumor development (Table I).

Chromosome study was performed at the same passage (passage 39) of RC-77T/E and RC-77N/E cell lines (Fig. 2C). Both cell lines are similar; near diploid human male (XY) with most chromosome counts in the 45-48 range. The modal number of the $\mathrm{RC}-77 \mathrm{~T} / \mathrm{E}$ cell line is 48 whereas the modal number of RC-77N/E cell line is 46 . Single $X$ and $Y$ in each karyotype of both cell lines is observed. Eight marker chromosomes were found in RC-77T/E cell line. Compared to $\mathrm{RC}-77 \mathrm{~N} / \mathrm{E}$ cell line, $\mathrm{RC}-77 \mathrm{~T} / \mathrm{E}$ cell line shows new changes in marker M1 as M1B and one copy of normal chromosomes 15 and 16 as marker M6 and M5, gaining p+ and q+ extra material, respectively (Table II and Fig. 2C). Only six marker chromosomes were found in the RC-77N/E cell line including those found the same marker chromosomes $(\mathrm{M} 1=\operatorname{del}(4)(\mathrm{q} 28 \mathrm{q} 34)+\mathrm{hsr}$ in some, $\mathrm{M} 1 \mathrm{~A}=\mathrm{t}(4 \mathrm{q} ; ?), \mathrm{M} 2=\mathrm{der}$ (9?), M2A=del(M2p-), M3=isoz(?) and M4=der(22?) detected in the RC-77T/E cell line.

\section{Discussion}

The present study appears to represent the first documented case of immortalized human prostate epithelial cell lines established from a pair of non-malignant and malignant tumor-derived from an African American prostate cancer patient. The immortalized RC-77T/E and RC-77N/E cells show a epithelial morphology and are grown in serum-free medium. The RC-77T/E cells form three dimensional spheroids whereas the RC-77N/E cells do not form the spheroids. The $\mathrm{RC}-77 \mathrm{~T} / \mathrm{E}$ cells produced tumors in SCID mice whereas the RC-77N/E cells produced no tumors in SCID mice. Both cells expressed NXK3.1, CK8, AR, p16 but did express PSA in mRNA level underlying monolayer culture (Table I). They showed androgen-responsiveness when treated with synthetic androgen (R1881) (Fig. 1B). Both cell lines are cytogenetically similar, near diploid human male (XY). However, RC-77T/E cell line has new marker chromosomes, $(\mathrm{M} 1 \mathrm{~B}=\mathrm{del} / \mathrm{t}(4$ ?)(q28;?), $\mathrm{M} 5=16 \mathrm{q}+$ and $\mathrm{M} 6=15 \mathrm{p}+)$ in addition to those observed in the RC77N/E cell line $(\mathrm{M} 1=\operatorname{del}(4)(\mathrm{q} 28 \mathrm{q} 34)+\mathrm{hsr}$ in some, $\mathrm{M} 1 \mathrm{~A}=\mathrm{t}(4 \mathrm{Q} ;$ ?),M2=der(9?),M2A=del(M2p-),M3=iso(?), M4=der(22?). To date only two models (MDA PCa and E006AA) of African American prostate cancer-derived human prostate cancer cell lines exist $(3,4)$. MDA PCa cell lines were derived from a single bone metastasis. E006AA cell line was established from a patient with a clinically localized prostate cancer. However, this cell line is not tumorigenic in nude mice. Thus, the cell lines described here represent better models for studying African American prostate cancer since they reflect accurately the in situ characteristics of malignant epithelium.

The distinct phenotypic differences were observed between these RC-77T/E and RC-77N/E cell lines. The RC-77T/E cell line derived from malignant tumor was able to form larger three dimensional spheroids in RWV system and form tumors in SCID mice compared to RC-77N/E cell line. However, the $\mathrm{RC}-77 \mathrm{~N} / \mathrm{E}$ cell line derived from non-malignant tissue was unable to form three dimensional spheroids and did not form tumors in SCID mice. Prostate cancer cells grown in the RWV system has reliably been utilized to mimic in vivo tumor formation. This property was correlated with the formation of tumor in SCID mice as shown above. Histopathological analysis shows that tumor induced by $\mathrm{RC}-77 \mathrm{~T} / \mathrm{E}$ cells are highly atypical poorly-differentiated adenocarcinoma (Fig. 2B) with cohesive groups of malignant cells extensively infiltrating the surrounding tissues.

Some of the alteration of chromosomes observed in RC$77 \mathrm{~T} / \mathrm{E}$ and $\mathrm{RC} 77 \mathrm{~N} / \mathrm{E}$ cell lines have been already reported in the literature. The presence of a marker chromosome involving in chromosome $4(\mathrm{M} 1=\operatorname{del}(4)(\mathrm{q} 28 \mathrm{q} 34)+\mathrm{hsr}$ in some) in both cell lines has been reported in other African American derived metastatic prostate cancer cell line (MDA $\mathrm{PCa})$ and a primary African American prostate cancer cell line, E006AA $(3,4)$. However, the observation of a common karyotypic pattern (regional deletion of 13q, 5q, 16q and 8p and gains of $8 \mathrm{q}$ and $5 \mathrm{q}$ ) of primary prostate cancer derived from African American men and Caucasian American men led to the conclusion that biological interracial differences among the prostate cancer patients are not due to gross chromosomal alterations (15). The determination of specific genetic markers involved in African American prostate cancer needs further detailed studies.

It is interesting to note that $4 \mathrm{q}$ alteration observed in both cell lines is the change also observed chromosome change in an established human prostate cancer cell line derived from primary tumor of a familial prostate cancer patient (5). Possible evidence of a prostate cancer susceptibility locus on chromosome $4 \mathrm{q}$ has been reported (16). As has been described, new marker chromosomes $(\mathrm{M} 5=16 \mathrm{q}+$ and $\mathrm{M} 6=15 \mathrm{p}+$ ) were observed in tumorigenic $\mathrm{RC}-77 \mathrm{~T} / \mathrm{E}$ cell line in addition to those observed non-tumorigenic RC-77N/E cell line $(\mathrm{M} 1=\operatorname{del}(4)(\mathrm{q} 28 \mathrm{q} 34)+\mathrm{hsr}$ in some, $\mathrm{M} 1 \mathrm{~A}=\mathrm{t}(4 \mathrm{q} ; ?)$, M2=der(9?), M2A=del(M2p-), M3=ios(?), M4=der(22?) (Fig. 2C and Table II). Interestingly, the marker chromosome $15+$ has been observed in a tumorigenic primary tumor-derived human prostate cancer cell line (17) whereas the marker chromosome $16 \mathrm{q}$ is the most frequent region alteration observed in primary prostate cancer $(18,19)$.

The results obtained here have demonstrated that these immortalized non-malignant and primary prostate tumorderived cell lines retain their original phenotypes and express some of their prostate-specific markers. Additionally, these models retained their androgen-responsive properties which ultimately will be useful to answer questions of therapeutics targeted at AR. Furthermore, this is the first African American primary prostate cancer cell line that retains ability to generate tumors in vivo. These novel findings fill much-needed void in prostate cancer and health disparities research. To our knowledge, this is only model with such properties and may offer unique opportunity for the study of early stage of African American prostate cancer development.

\section{Acknowledgements}

This study was supported by the National Institute of Health (U54 CA118623 and RR-G12RR03059 to T.T and C.Y), a Department of Defense Prostate Cancer Research Program 
(PC030694 to J.S.R.) and PC07397 (Department of Defense) to C.Y.

\section{References}

1. Jemal A, Siegel R, Ward E, Murray T, Xu J and Thun MJ: Cancer statistics, 2007. CA Cancer J Clin 57: 43-66, 2007.

2. Moul JW: Screening for prostate cancer in African Americans. Curr Urol Rep 1: 57-64, 2000.

3. Navone NM, Olive M, Ozen M, et al: Establishment of two human prostate cancer cell lines derived from a single bone metastasis. Clin Cancer Res 3: 2493-2500, 1997.

4. Koochekpour S, Maresh GA, Katner A, et al: Establishment and characterization of a primary androgen-responsive AfricanAmerican prostate cancer cell line, E006AA. Prostate 60 $141-152,2004$

5. Yasunaga Y, Nakamura K, Ewing CM, Isaacs WB, Hukku B and Rhim JS: A novel human cell culture model for the study of familial prostate cancer. Cancer Res 61: 5969-5973, 2001.

6. Galloway DA and McDougall JK: Human papillomaviruses and carcinomas. Adv Virus Res 37: 125-171, 1989.

7. Xu LL, Srikantan V, Sesterhenn IA, et al: Expression profile of an androgen regulated prostate specific homeobox gene NKX3.1 in primary prostate cancer. J Urol 163: 972-979, 2000

8. Wells A, Souto JC, Solava J, Kassis J, Bailey KJ and Turner T: Luteinizing hormone-releasing hormone agonist limits DU-145 prostate cancer growth by attenuating epidermal growth factor receptor signaling. Clin Cancer Res 8: 1251-1257, 2002.

9. Sung SY, Hsieh CL, Law A, et al: Coevolution of prostate cancer and bone stroma in three-dimensional coculture: implications for cancer growth and metastasis. Cancer Res 68: 9996-10003, 2008 .
10. Yates C, Wells A and Turner T: Luteinising hormone-releasing hormone analogue reverses the cell adhesion profile of EGFR overexpressing DU-145 human prostate carcinoma subline. Br J Cancer 92: 366-375, 2005

11. Hukku B and Rhim JS: Role of chromosome 5 in immortalization and tumorigenesis of human keratinocytes. Cancer Genet Cytogenet 68: 22-31, 1993.

12. International System for Human Cytogenetic Nomenclature. In: An International System for Human Cytogenetic Nomenclature. Mitelman F (ed). S. Karger, Basel, 1995.

13. Sung SY, Hsieh CL, Law A, et al: Coevolution of prostate cancer and bone stroma in three-dimensional coculture: implications for cancer growth and metastasis. Cancer Res 68: 9996-10003, 2008.

14. Wang R, Xu J, Juliette L, et al: Three-dimensional co-culture models to study prostate cancer growth, progression, and metastasis to bone. Semin Cancer Biol 15: 353-364, 2005

15. Cher ML, Lewis PE, Banerjee M, et al: A similar pattern of chromosomal alterations in prostate cancers from AfricanAmericans and Caucasian Americans. Clin Cancer Res 4: 1273-1278, 1998

16. Smith JR, Freije D, Carpten JD, et al: Major susceptibility locus for prostate cancer on chromosome 1 suggested by a genomewide search. Science 274: 1371-1374, 1996.

17. Ko D, Gu Y, Yasunaga Y, et al: A novel neoplastic primary tumor-derived human prostate epithelial cell line. Int J Oncol 22: 1311-1317, 2003.

18. Carter BS, Carter HB and Isaacs JT: Epidemiologic evidence regarding predisposing factors to prostate cancer. Prostate 16: 187-197, 1990.

19. Kunimi K, Bergerheim US, Larsson IL, Ekman P and Collins VP: Allelotyping of human prostatic adenocarcinoma. Genomics 11: 530-536, 1991. 